Acta Poetica $26(1-2)$

PRIMAVERA-OTOÑO

2005

\title{
Elaboraciones literarias cultas y populares sobre lo "homosexual" en el cambio del siglo xIx al xx en México
}

\author{
José Ricardo Chaves
}

\begin{abstract}
A partir de dos textos populares, "El ánima de Sayula" y el "Romance de los 41", se revisan en este ensayo las variaciones en México de lo que a partir del siglo Xx se llamará "homosexualidad" y que, desde la perspectiva del siglo XIX, se enfocaba más bien como "afeminamiento".

Taking into consideration two popular texts: "El Ánima de Sayula" and "El romance de los 41", different versions are reviewed about how "homosexuality" was understood in Mexico from the XIX century perspective, when this current term was conceived rather as "effeminacy".
\end{abstract}


Acta Poetica 26 (1-2)

PRIMAVERA-OTOÑO

2005

José Ricardo Chaves

Instituto de Investigaciones Filológicas, UNAM

Elaboraciones literarias cultas y populares sobre lo "homosexual" en el cambio del siglo xix al xx en México

Lo que hoy se denomina homosexualidad (masculina) no es algo fijo en el tiempo. Cada sociedad, en una cierta época, genera su propio modo de ver, tratar y nombrar la no aceptación por un hombre del patrón masculino ("heterosexual") de su momento y la consiguiente desviación. De hecho, filológicamente "homosexual" se acuña en la segunda mitad del siglo XIX, en el ambiente médico, mientras que "gay" es un término de la segunda mitad del siglo xx. Como las palabras no son inocentes, la primera designación implicó una impronta taxonómica y psiquiátrica, la búsqueda de un nombre para una "enfermedad", mientras que la segunda, al ser una denominación elegida por los propios aludidos, tiene un matiz de defensa y autonomía sexuales.

En el siglo xix mexicano, al menos en su literatura, el gay u homosexual tal como se entiende hoy, a principios del siglo XXI (un hombre que tiene o quisiera tener relaciones sexuales con otro hombre), no aparece, no existe, pero hay su equivalente: el afeminado, un desviante de la norma masculina hegemónica, que compite en coquetería y locuacidad con las mujeres, aunque sin llegar a tener relaciones sexuales con otro 
hombre. En este sentido, el afeminado se define por un comportamiento social (gestos, gusto por la ropa, el baile y los perfumes...) y no por una práctica sexual. Eróticamente se mantiene en lo heterosexual, pero su conducta es anómala y ambigua. En una sociedad de visión naturalista donde los seres humanos sólo pueden ser hombres o mujeres, salirse de una de estas categorías solamente puede hacerse incorporándose a la opuesta, degradándose, lo que supone, desde el punto de vista imperante, aplicar la violencia a quien transgreda la convención sexual, ya por la cara "benigna" (ridículo, humor, burla, albur), ya por la faz oscura (represión, hoguera, linchamiento, campo de concentración).

Durante la Colonia, el término para el "pecado nefando" (sexo entre hombres) fue "sodomía", por lo que el afeminado decimonónico se encuentra ubicado entre el sodomita colonial y el homosexual o gay de los tiempos modernos. Es interesante observar cómo el discurso colonial sí alude directamente (para reprimirlo) al hombre que tiene sexo con hombres, mientras que el siglo XIX calla, lo evade o lo ridiculiza sin nombrarlo por medio del afeminado. Por supuesto, el término sodomía antes del XIX tenía un registro semántico más amplio del que manifiesta hoy, en que alude básicamente al sexo anal (con lo que no necesariamente implica una relación homosexual puesto que puede darse en una pareja heterosexual). Al decir de Boswell:

Probablemente su etimología sea un error de la historia, y en diversas épocas y en distintos lugares lo ha connotado todo, desde el coito heterosexual ordinario en una posición atípica, hasta el contacto sexual oral con animales. En algunos momentos de la historia se refirió casi exclusivamente a la homosexualidad masculina y en otros casi exclusivamente al exceso heterosexual. $(1998,470)$ 
Como el mismo Boswell señala, sodomía también incluyó en sus acepciones herejía, idolatría, islamofilia, esto es, aspectos religiosos y no sexuales, todo lo cual la torna una categoría escurridiza.

Habría que tener en cuenta que, aunque en el siglo XIX, a nivel culto, en la expresión literaria no hay homosexuales, sí hay afeminados, definidos más por el vestido que por la cama, esto es, más por cómo visten que por con quién se acuestan. A nivel popular la situación es distinta, pues en las canciones dichas o impresas hay personajes "putos" y "jotos", como categorías que identifican a cierto tipo de hombres, tal como ocurre en El ánima de Sayula de Teófilo Pedroza (1897), o en las cuartetas de Posada sobre "los 41", a propósito de la famosa fiesta de hombres vestidos de mujeres, unos, de hombres, otros, descubierta por la policía para gran escándalo social, en 1901. Curiosamente, en el primer texto, menos circunstancial y más tradicional, la condición de puto nada tiene que ver con afeminamiento sino con sexo anal. Es el segundo, más urbano y político, y que acompaña el grabado de Posada, el que sí los amarra definitivamente.

Los afeminados del XIX son equivalentes a los homosexuales del xx, en términos de cuestionamiento del binarismo sexual, pero no lo hacen con base en prácticas sexuales que los diferencien y los identifiquen como una especie distinta (como ocurrirá en los discursos posteriores sobre lo homosexual y sobre lo gay, coincidentes en esto pero muy distintos en otras cosas), sino por medio de una conducta peculiar para su género, a través de una preocupación desmedida por la propia imagen en términos de vestido, peluquería, cosméticos, zapatos, así como por el gusto por asuntos mundanos pero improductivos, como el baile, la fiesta, la seducción... o la lectura. Su conducta, no su gusto sexual, los asemeja al sexo opuesto, a las mujeres: de aquí su "afeminamiento". No se acuestan con hombres, aunque tal vez algunos lo quisieran secretamen- 
te. La mayoría sí lo hacen con mujeres (seducirlas es su oficio) y algunos pocos, como Chucho el Ninfo, parecen gozar de una castidad narcisista. En todo caso, estos afeminados literarios del XIX no se definen por con quién tienen relaciones sexuales sino por unos rasgos de conducta considerados propios del sexo opuesto pero que, sin embargo, no los exilian totalmente del campo masculino, aunque sí los disminuyen, los degradan, los tornan no hombres sino apenas hombrecitos.

Buena parte de esta disminución de la masculinidad, de este aniñamiento, se da desde los nombres de los personajes, generalmente con diminutivos, o bien formas coloquiales: el Manolito del cuento de Rodríguez Galván ("Manolito el pisaverde"); el Josecito de El fistol del diablo de Manuel Payno; Pablito y Chucho el Ninfo, de la novela de José T. de Cuéllar, por ejemplo. Por su preocupación excesiva por su imagen, parecen narcisos que no quieren (o no pueden) crecer, que se encuentran estancados en una etapa de infancia o adolescencia, lo que nos remite a la interpretación freudiana de la homosexualidad como desarrollo detenido de la libido. Sin duda el más grande afeminado de la literatura mexicana del XIX es Chucho el Ninfo, el personaje creado por Cuéllar, tanto que da título a la novela de 1871. Aquí se desarrolla con mayor detalle el imaginario del afeminado y se reúnen elementos sueltos en otros textos y se les da una mejor organización simbólica.

En toda esta literatura culta no hay hombres que tengan sexo con hombres, pues este asunto es de suyo nefando, indeseable, por lo que ni siquiera se les nombra por cuestiones de buenas maneras literarias. Será con el modernismo de los últimos años del siglo cuando se comience a escribir del asunto erótico con más audacia. Que no se hablara de ello en las letras no significa que no hubiera una cierta conciencia social sobre estos hombres desviantes (afeminados) que todavía no son desviados (homosexuales), pues este término se usará hasta el siglo xx, a la sombra de la psiquiatría. También el término "invertido" gustará en 
esos ámbitos psicológicos y sexológicos y alude a alguien que va en dirección contraria, al revés de los otros, los "normales".

A diferencia del lenguaje culto, el popular usa o crea términos específicos todavía imperantes hoy, como "puto" y "joto", el primero de larga data en el español, por lo menos desde el siglo Xv, según Corominas (1961), de espectro semántico variado aunque se perfila sobre todo como "sodomita" o "pasivo" (en el acto sexual), y que llega a México con la conquista española. De hecho el Diccionario de mejicanismos de Francisco Santamaría (1959), lo incorpora (no así joto) de la siguiente manera: "Puto: invertido, afeminado puerco; tipo enfermizo y teratológico del pederasta o sodomita". Nótese en esta definición de diccionario que parece más bien insulto personal cómo la decimonónica palabra "afeminado" se presenta rodeada de un nuevo lenguaje, ya más del siglo xx, vinculado a la inversión, la enfermedad y la teratología; aparecen también la antigua palabra "sodomita" y la intemporal de "puerco", que, aplicada a un humano, no sólo lo animaliza sino lo torna en algo sucio, como corresponde a dicho animal. Si un puto es un afeminado puerco, entonces quiere decir que hay afeminados que no son puercos y que por lo tanto tampoco son putos: Chucho es un buen ejemplo. Dado que la diferencia entre los dos tipos de afeminados es el contacto sexual con otro hombre, entonces la calidad de puerco estriba en tener o no dicho contacto.

Un ejemplo de uso popular de "puto" lo encontramos en un relato en verso de fines del XIX en Michoacán titulado El ánima de Sayula (1897) de Teófilo Pedroza. Según afirma A. Jiménez en su libro Picardía mexicana, se trata de un relato

que aunque poco difundido entre gente refinada, tiene la virtud de ser la poesía más conocida en nuestro país, por encima de las mejores de Sor Juana, López Velarde, Antonio Plaza y Amado Nervo. Varios millares de personas del pueblo la recitan de memoria, sin haber visto ni el forro de un ejemplar, y lo que es más, a pesar de que muchas de ellas no saben leer. $(1962,151)$ 
Jiménez señala que "se han publicado varios centenares de versiones un tanto diferentes", e incluso hace la suya propia, que no es la usada por mí en este escrito, pues no sólo es algo más corta que otra versión encontrada en internet (véase la referencia precisa del sitio en la bibliografía), sino que también atempera su posible procacidad inicial, en vista a un público lector más educado. Tanto este texto, como el que después revisaremos, el romance de los 41, pertenecen a lo que Aurelio González llama textos "vulgares" ( tética), que, entre otros rasgos,

por lo general se difunden desde los centros urbanos, y recogen comúnmente un ideario de las clases dominantes en temas que habitualmente son de "crónica negra" (o "nota roja") como catástrofes, crímenes, aventuras sentimentales desgraciadas, acontecimientos escandalosos, etc. En este tipo de textos [...] toma parte la transmisión impresa a través de pliegos y hojas volantes vendidos por sus transmisores (intérpretes ambulantes —en ocasiones ciegos- más o menos profesionalizados). El lenguaje de estos textos no es el natural de la oralidad y por tanto se memorizan tal cual limitando la creatividad poética. (2002, 102-103)

Atendiendo a la distinción de Menéndez Pidal señalada por González entre literaturas popular y tradicional, con base en una mayor fijeza textual en el caso de la primera, pues la segunda "se rehace en cada repetición", "se refunde en cada una de sus variantes", en el caso de El ánima de Sayula estaríamos más cerca de lo tradicional que de lo popular pues, según señalé, está caracterizada por una gran cantidad de versiones.

En este relato un vivo ansioso de fortuna enfrenta a un fantasma que, a cambio de la riqueza pedida, quiere su "fundillo". Así se presenta el fantasma: 
Me llamo Perico Súrres

- dijo el fantasma en secreto-

fui en la tierra un buen sujeto,

muy puto mientras viví.

Y a continuación hace su pedido de manera directa y casi procaz:
Ando ahora penando aquí, en busca de un buen cristiano que con la fuerza del ano me arremangue el mirasol. El favor que yo te pido es un favor muy sencillo: que me prestes el fundillo tras del que ando tiempo ha. Las talegas que tú buscas aquí te las traigo colgando; ya te las iré arrimando a la puerta del fogón...

Aquí la condición de "puto" está inequívocamente relacionada con el contacto sexual de tipo anal, sodomía en su forma clásica, no con afeminamiento, delicadeza o sensibilidad: "arremangar el mirasol con la fuerza del ano" alude a la retracción del prepucio en el pene erecto (el mirasol) que penetra; las talegas que cuelgan son los testículos que se acercan, durante la penetración, a "la puerta del fogón" (el ano). Tan es así que, en la moraleja final, se dan recomendaciones al lector:

$$
\begin{aligned}
& \text { y por vía de precaución } \\
& \text { llévate como cristiano } \\
& \text { la cruz bendita en la mano } \\
& \text { y en el fundillo un tapón. }
\end{aligned}
$$

La versión de Jiménez (compuesta en 1947) acaba de otra forma: 


$$
\begin{aligned}
& \text { y para tu garantía } \\
& \text { pon el cuchillo adelante } \\
& \text { y sin perder un instante } \\
& \text { repliégate a la pared. }
\end{aligned}
$$

En ambos casos, se trata de proteger el ano, ya con un tapón, ya con la pared, aunque el objeto que se adelanta y se esgrime varíe: una cruz y un cuchillo, una más defensiva, el otro más agresivo. Además, la cruz está vinculada con lo religioso, quizá por el origen y contexto más rural de la historia en sus inicios. Según se señala en el sitio de internet: "No es extraño que este relato recibiera la bendición de la Iglesia, dado su contenido moralizante: tradicionalmente, en México la sodomía activa no ha estado estigmatizada entre las clases populares, pero desde el XIX sí ha sido condenada por la psiquiatría oficial y la moral religiosa. El cuento es aún muy popular en el país, y se recita con frecuencia".

Pasemos ahora al segundo texto. En pleno porfirismo, en 1901, se produce el escándalo de los 41, un "baile de señores solos", de "afeminados", "de vestidos de mujeres" — según los títulos periodísticos-, un baile tan depravado que superaba incluso a los aquelarres medievales. Un artículo en el periódico El País, conservador y católico, usó en un solo párrafo las siguientes palabras para explicar su sentir sobre tal fiesta: "mal", "estragos del error", "libertinaje", "abismos de aberraciones", "sensualidad", "desenfrenada licencia", "liberalismo", “degeneración”, "frutos nefandos", “depravación”... Desde su óptica conservadora, el articulista aprovechó la ocasión para atacar al liberalismo porfirista, cuando vincula tales "aberraciones" con liberales y progresistas: la modernización propiciada por el régimen dictatorial sería responsable de tan lamentable estado de cosas.

La autoridad respondió con dureza exacerbada sobre los 41 detenidos, como para aplacar a las voces públicas acusadoras, y exilió a 19 de ellos a Yucatán, en medio de permanentes ve- 
jaciones, desde su detención hasta su traslado y confinamiento. Si no se fueron todos al exilio, fue porque hubo influencias y dinero de por medio, pues buena parte de ellos eran "hijos de buenas familias". En La Patria se lee este pasmo burgués: "Lo vergonzoso y altamente irritante es que entre los aprehendidos hay muchos que han figurado en el boulevard de Plateros", mientras El País habla de "jóvenes que día a día paseaban por los boulevards ostentando sus trajes perfectamente pagados a moda y llevando ricas joyas". Se trata, pues, de los famosos lagartijos, que antes eran afeminados y que ahora son jotos, o mejor en diminutivo, a la usanza mexicana: jotitos, como puede apreciarse en las cuartetas que acompañaron los grabados de José Guadalupe Posada sobre tal evento, impresos en hojas volanderas.

El primer grabado en hoja suelta llevaba los titulares: "Los 41 maricones encontrados en una baile de la Calle de la Paz el 20 de Noviembre de 1901. Aquí están los Maricones muy chulos y coquetones". Vienen luego catorce cuartetas distribuidas así: la primera es introductoria y nos avisa de "un gran baile singular", y las dos siguientes nos presentan de forma directa el asunto:

Cuarenta y un lagartijos
disfrazados la mitad
de simpáticas muchachas
bailaban como el que más.
La otra mitad con su traje,
es decir de masculinos,
gozaban al estrechar
a los famosos jotitos.

Se confirma así la sospecha popular sobre la conducta sexual de los lagartijos, dandis del modernismo de clases me-

* La fuente tanto de los artículos periodísticos como del romance de los 41 es el libro The famous 41 (2003). 
dias y altas, pues en esta composición quedan vinculados claramente "lagartijo" y "jotito". Después hay un desarrollo de cinco cuartetas (cinco de catorce es una buena proporción), en que viene la descripción de los hombres vestidos de mujer (fascinación masculina y fetichista por los objetos de la mujer): pelucas, abanicos, aretes, maquillaje, que me remiten al cuarto de don Francisco, el donjuán femíneo de El fistol... de Payno, donde también habían corsés y pechos postizos:

$$
\begin{aligned}
& \text { Llevaban buenos corsés } \\
& \text { con pechos bien abultados } \\
& \text { y caderitas y muslos... } \\
& \text { postizos... pues está claro. }
\end{aligned}
$$

Tras la descripción física y gestual, viene una cuarteta que apunta a mostrar su aspecto moral, que, por supuesto, deberá encender más la indignación del lector:

Se trataba, según dicen, de efectuar alegre rifa de un niño de catorce años, por colmo de picardías.

En los aquelarres y misas negras los niños eran sacrificados. También en la fiesta de los 41, aunque de otra forma. Quedan así unidos en el discurso afeminamiento y pedofilia, asunto que no tenía que ver con el evento histórico, aunque sí en la mente prejuiciada del autor de la glosa. Tras una cuarteta de transición se llega a otra que abre la represión:

pum! que los gendarmes entran

sorprendiendo a los jotones!

y aquello sí fue de verse...

¡qué apuros y qué aflixiones (sic)! 
Atrás quedaron los diminutivos de jotitos y mariquitos de cuartetas anteriores; ahora se tornan jotones a los que hay que reprimir y castigar, maricones y maricazos a los que hay que exiliar violentamente a Yucatán, como puede verse en otro grabado. Tras la represión, vienen dos cuartetas para describir la reacción de lágrimas, gritos y ladridos, y una última para decir que ningún jotón se escapó. Puede el lector porfirista quedar tranquilo.

Como vemos, ya sea en los sectores populares, ya en los conservadores y católicos de élite, se generan discursos de aberración y castigo, centrados en los afeminados o jotos, en un caso para acusar a las clases altas de corruptas, en el otro para mencionar los males liberales. En ambos sectores, cultos y populares, se observan discursos y actitudes que hoy llamamos homofóbicas, basadas en la discriminación, el escarnio y la represión. Se trata de una homofobia transclasista que apoyaría en parte lo dicho por González de no permitir "seguir la visión utópica bajtiniana que ve en el lenguaje y la risa populares una oposición a la autoridad" (104) (pues muchas veces ellos mismos son la expresión de esa autoridad, no su opuesto). Y acota el autor:

En este sentido la literatura tradicional tiende a ser predominantemente conservadora ya que va a ser el vehículo idóneo para mantener los valores colectivos que garantizan la permanencia ordenada de la comunidad [...]. Los textos literarios tradicionales y populares no son por sí mismos manifestaciones de resistencia cultural, social o política, sino la expresión - dentro de la cultura de la oralidad, ya que normalmente el acceso de los sectores rurales o económicamente débiles a otras formas culturales está mucho más restringido- de los valores aceptados de una comunidad, en una doble vertiente de conservación y refuncionalización. $(2002,104)$

Las clases subordinadas acogen o comparten intereses y valores de las dominantes, "descontextualizados y adaptados a 
los esquemas generales aceptados por la comunidad rural o alejada de los grandes núcleos urbanos" (104). En el caso de esta homofobia compartida tiene que ver la influencia católica común, incluso en el ámbito secular, pues los liberales del XIX no son menos "homófobos" que los católicos de la época. Después del escándalo de los 41 , que tornó visible una sexualidad masculina con los pares de género y no sólo una conducta amanerada, la sociedad mexicana se vio en la necesidad de nombrar eso que se esquivaba entre los tules y sedas del afeminamiento, para dar cabida a nuevas formas de pensar lo sexual y a una nueva categoría: al decir de Carlos Monsiváis, se da "la invención de la homosexualidad en México" (Novo 1998).

Llama la atención que tal categoría surja en un contexto de escándalo, pero lo mismo pasaba en Europa: piénsese en el caso de Oscar Wilde en la sociedad inglesa. Pareciera que la modernidad exigió cuando menos un crujir de la estructura social, pasar del discurso al acto, la confrontación con la ley, el castigo, el oprobio y el escándalo, para que la categoría de lo homosexual calara en las culturas victoriana y porfirista e impusiera su propio espacio discursivo.

Más adelante, en el ámbito de las polémicas estéticas y políticas del México posrevolucionario, se aplicará tal categoría, no tanto a los modernistas sino a una generación literaria posterior, a los Contemporáneos. A lo más que llegaron los poetas del modernismo fue al dandismo amanerado, a cierto lagartijismo decadente, excepto en el caso de un autor más bien tardío en ese movimiento y que murió en México, el colombiano Porfirio Barba Jacob, quien expresó de forma clara y directa en poesía y vida su propio homoerotismo, vivido bajo el signo de la culpa, pero al menos vivido, no reprimido, como pudo haber sido en otros casos.

En esta línea argumentativa, resulta muy ilustrativo el encuentro narrado por Salvador Novo, futuro "Contemporáneo" entonces muy joven, en sus memorias tituladas La estatua de 
sal. Novo y Xavier Villaurrutia (otro Contemporáneo) reciben en su estudio, entre otros, al escritor hondureño Rafael Heliodoro Valle y al colombiano Barba Jacob, en cuyo encuentro la poesía y la homosexualidad tienen un lugar destacado. Dice Novo de Barba Jacob:

$\mathrm{Su}$ fealdad me fue tan inmediatamente repulsiva como su incongruente descaro. Le pregunté si le gustaba no sé ya qué poeta; y "Lo que a mí me gusta es que me penetren duro" — dijo con su belfo grueso y amoratado. Luego sacó cigarros, nos dio, encendimos, chupé - tres veces, sosteniendo el aire, nos instruía. Empezó a recitar sus versos. Yo miraba a la calle. El tiempo se había suspendido. La luz era blanca, blanca, en el absoluto, sordo silencio. $(1998,106)$

Por supuesto, los cigarrillos de Barba Jacob eran de marihuana, pues él era un notorio y conocido fumador de canabis, y su consumo llevó al desmayo a Novo. Sin embargo, Barba Jacob no sólo era conocido por sus gustos canábicos sino también homosexuales, sobre los que incluso él mismo llegó a hablar y, de manera pionera en América Latina, a escribir y a nombrar poéticamente. De hecho, en aquel encuentro los intereses sexuales estaban actuando (cuando menos, por parte de algunos de los ahí presentes). No obstante hay una diferencia importante: mientras que Barba Jacob es un hombre maduro (va a cumplir cuarenta años), Novo es un joven de 17 años. El primero, aunque manifieste públicamente su homosexualidad, vive su condición a la luz de la culpa y el pecado; el segundo, veinte años más joven, muy rápido descubre y acepta su preferencia sexual, no sin una cuota de angustia y dolor, aunque al final el resultado sea una aceptación casi gozosa (dada su visión menos religiosa, más secular). En síntesis, se trata de un encuentro generacional: modernistas por un lado, Contemporáneos por el otro, en el que la homosexualidad está siendo vivida, dicha y escrita de manera muy distinta, lo que habla de 
un cambio de paradigma en cuanto a cómo interpretar tal desviación o preferencia sexual, entre un siglo xIX que la enfoca a la luz de lo religioso (el pecado y la culpa) y un siglo xx que lo hará con una visión más secular, ya como enfermedad, ya como "preferencia".

En todo caso, estas metamorfosis hacia la homosexualidad están ocurriendo sobre todo a nivel de la literatura culta pues, a nivel popular, siguieron vigentes en el nuevo siglo los estereotipos de lo homosexual (ya sea en tanto joto, o puto o, más recientemente, "gay") en términos de afeminamiento y analidad, al menos si se juzga a partir de muchas manifestaciones de la cultura popular en cine, televisión, radio o prensa escrita. Que sobreviva el estereotipo del homosexual como afeminado no significa que no tenga también sus cambios pues, en un ambiente de mayor secularización, ya no se le vincula tanto con el pecado y el vicio, sino más bien con la enfermedad, la risa y la democracia (en tanto derechos humanos).

Hay que reconocer también que, en el nuevo siglo, los propios involucrados retomaron en sus formulaciones de identidad estos aspectos afeminados, ya no como boba mímesis de lo supuestamente femenino (según lo hizo el discurso literario del XIX), sino como artilugio de imagen para transgredir el orden social, como a su manera habían hecho en el siglo XIX los dandis, afeminados y lagartijos. La voz heteronormativa del XIX ridiculizó y censuró un modelo masculino disminuido. En el $\mathrm{xx}$, las voces de los antes descritos y que ahora se describían a sí mismos, a veces retomaron esos rasgos afeminados pero con connotaciones más críticas y reivindicativas. Ya no se buscó la risa que denigraba sino la que hacía reflexionar o la que asustaba. En el nuevo siglo el antes afeminado solitario padeció metamorfosis que, en la segunda mitad de la centuria, lo multiplicó, lo transformó en legión de homosexuales, de gays, de travestis, de transexuales, en fin, el variopinto espectro de la diversidad sexual. 


\section{REFERENCIAS}

Boswell, John, 1998. Cristianismo, tolerancia social y homosexualidad, Barcelona, Muchnik Editores (Biblioteca Atajos).

Corominas, Joan, 1961. Breve diccionario etimológico de la lengua castellana, Madrid, Gredos.

Cuéllar, José T. de, 1947. Historia de Chucho el Ninfo, ed. y pról. de Antonio Castro Leal, México, Porrúa (Colección de Escritores Mexicanos).

GonZÁlez, Aurelio, 2002. "Poética de lo marginal: entre lo popular y lo culto", en La otra Nueva España. La palabra marginada en la Colonia, Mariana Masera (coord.), Barcelona, UNAM/Azul Editorial, pp. 101-108.

Irwin, Robert Mc Kee, Edward J. McCaughan y Michelle Rocío NASSER (eds.), 2003. The Famous 41. Sexuality and Social Control in Mexico, 1901, New York, Palgrave MacMillan.

Jiménez, A., 1962. Picardía mexicana, México, Libro Mex Editores.

Novo, Salvador, 1998. La estatua de sal, pról. de Carlos Monsiváis, México, Conaculta.

Pedroza, Teófilo 2004 [1897]. "El ánima de Sayula” en Identidades. Centro de estudios de Género y sexología, http://www.identidades.org/literatura/sayula.htm.

Santamaría, Francisco Javier, 1959. Diccionario de mejicanismos, México, Porrúa. 